\title{
Long non-coding RNA HAGLROS regulates the proliferation, migration, and apoptosis of esophageal cancer cells via the HAGLROS-miR-206-NOTCH3 axis
}

\author{
Ling Gai ${ }^{1,2 \#}$, Yeqing Huang ${ }^{2 \#}$, Lingling Zhao ${ }^{3}$, Feng Li $^{4}$, Zhixiang Zhuang ${ }^{1}$ \\ ${ }^{1}$ Department of Oncology, The Second Affiliated Hospital of Soochow University, Suzhou, China; ${ }^{2}$ Department of Chemotherapy, Affiliated \\ Hospital of Nantong University, Nantong, China; ${ }^{3}$ Department of Medical Ultrasound, The First People's Hospital of Nantong, Nantong, China; \\ ${ }^{4}$ Department of Laboratory Medicine, Affiliated Hospital of Nantong University, Nantong, China \\ Contributions: (I) Conception and design: Z Zhuang, F Li; (II) Administrative support: Z Zhuang; (III) Provision of study materials or patients: Y \\ Huang; (IV) Collection and assembly of data: L Gai, Y Huang, L Zhao; (V) Data analysis and interpretation: L Gai, F Li; (VI) Manuscript writing: \\ All authors; (VII) Final approval of manuscript: All authors. \\ "These authors contributed equally to this work. \\ Correspondence to: Zhixiang Zhuang. Department of Oncology, The Second Affiliated Hospital of Soochow University, No. 1055 Sanxiang Road, \\ Gusu District, Suzhou 215004, China. Email: zzx22066@163.com; Feng Li. Department of Laboratory Medicine, Affiliated Hospital of Nantong \\ University, Xisi Road 20\#, Nantong 226001, China. Email: 540870553@qq.com.
}

Background: Esophageal cancer (EC) is a common malignant tumor of the digestive tract, the treatment of which involves surgery combined with radiotherapy and chemotherapy, as well as other comprehensive types of treatment. The pathogenesis of EC remains unclear, which hinders the development of clinical therapy and the identification of molecular targets for this disease. Long non-coding RNAs (lncRNAs) have been shown to be associated with the malignant biological behavior of EC, but the specific molecular mechanisms underlying the carcinogenesis of EC are not fully understood.

Methods: Reverse transcription-quantitative PCR (RT-qPCR) was applied to measure the lncRNA HAGLR opposite strand lncRNA (HAGLROS) levels in EC cell lines and tissues. Cell Counting Kit8 (CCK-8) detection, scratch test, and Transwell assay were performed to determine the proliferation, migration and invasion of EC cell. The interaction between HAGLROS, microRNA (miR)-206, and notch receptor 3 (NOTCH3) was confirmed by RNA immunoprecipitation and dual luciferase reporter gene assays. Results: HAGLROS is upregulated in esophageal squamous cell carcinoma (ESCC) tissues and predicts poor prognosis. Silent HAGLROS is negatively associated with malignant behavior in EC cells. Low expression of HAGLROS can induce decreased invasive and migratory abilities in EC cells. Downregulated HAGLROS significantly inhibits the proliferation of EC cells and accelerates apoptosis. HAGLROS promotes EC cell tumorigenesis in vivo. HAGLROS participates in the HAGLROS/miR-206/NOTCH3 regulatory axis in EC cells.

Conclusions: HAGLROS may play a role in the progression of EC by modulating the miR-206/NOTCH3 signaling axis, and may be a novel target for the diagnosis and treatment of EC.

Keywords: Long non-coding RNA (lncRNA); HAGLR opposite strand lncRNA (HAGLROS); microRNA-206 (miR-206); notch receptor 3 (NOTCH3); esophageal carcinoma

Submitted Aug 10, 2021. Accepted for publication Oct 09, 2021.

doi: 10.21037/jgo-21-586

View this article at: https://dx.doi.org/10.21037/jgo-21-586 


\section{Introduction}

Esophageal cancer (EC) is one of the most common gastrointestinal tumors, with metastasis accounting for the majority of mortality associated with EC (1). The standard treatment for localized EC is radiotherapy and chemotherapy, followed by surgery, but the recurrence rate is still high. In addition, about $50 \%$ of patients with EC present with unresectable or metastatic disease (2). In the past decade, although considerable progress has been made in the prevention and control of various tumors, such as lung cancer and breast cancer, the overall 5 -year survival rate of EC patients is still less than $20 \%$ and the incidence rate is rising rapidly worldwide (3-5). Thus, the identification of key molecules involved in EC is urgently needed to improve the clinical outcome.

Previous studies have shown that the majority of the human gene transcriptome is composed of non-coding RNAs (ncRNAs), which lack an open reading frame and protein-coding function (6). Depending on the nucleotide (nt) length, ncRNAs can be divided into short chain ncRNAs (<200 nt) and long ncRNAs (lncRNAs, >200 nt) (7). Studies have shown that IncRNAs play a key role in tumor cell proliferation, apoptosis, invasion, and metastasis (8-10). MicroRNAs (miRNAs/miRs) are a class of small, endogenous ncRNAs of 18-25 nt that cause degradation or translation inhibition of target genes by pairing with bases located in the 3'-untranslated region (3'-UTR) of the target gene (11). Multiple studies have shown that miRNAs are involved in the regulation of various cellular biological processes, including tumorigenesis and cancer metastasis $(12,13)$. It has been reported that lncRNAs function as competitive endogenous RNAs (ceRNAs) regulating miRNAs, thereby inhibiting the translation or degradation of target genes and facilitating tumor progression (14). For example, upregulated MIR205 host gene in cervical cancer regulates cell proliferation, migration, and apoptosis at the cellular level by modulating the miR-122-5p/forkhead box P2 axis as a ceRNA for EC progression, and plays a tumorigenic role (15). Distal-less homeobox 6 antisense RNA 1 (AS1) upregulates the expression of proline rich 11 by acting as a ceRNA of miR-144 in non-small cell lung carcinoma (NSCLC) cells, thus inhibiting tumor growth in NSCLC in vivo (16).

The present study was focused on the lncRNA HAGLR opposite strand lncRNA (HAGLROS), which has been identified as a ceRNA in gastric, liver, colon, and nasopharyngeal cancer, where it helps to maintain the malignant phenotype of tumor cells (17-20). HAGLROS enhances the development of nasopharyngeal carcinoma by modulating miR-100/autophagy related 14 axismediated PI3K/AKT/mTOR signaling (20). However, the mechanism of $H A G L R O S$-mediated regulation in EC remains unclear.

The present study investigated the effect of the HAGLROS gene on the proliferation, migration, and apoptosis of EC cells by silencing the expression of HAGLROS. It is the first time to explore the influence of HAGLROS/miR-206/NORCH3 signal axis on the occurrence and development of EC. The aim of the present study is to provide a novel theoretical basis for the diagnosis and treatment of EC.

We present the following article in accordance with the ARRIVE reporting checklist (available at https://dx.doi. org/10.21037/jgo-21-586).

\section{Methods}

\section{Patients and tissue samples}

From December 2011 until June 2013, 76 patients with EC underwent surgery at The Affiliated Hospital of Nantong University. Paired esophageal squamous cell carcinoma (ESCC) and adjacent normal tissues were obtained from the patients. The diagnosis of EC was based on histopathological evaluation. Patients who received preoperative radiotherapy or chemotherapy were excluded, and adenocarcinoma and small cell carcinoma of the esophagus were also excluded. All collected tissue samples were immediately frozen in liquid nitrogen and stored at $-80{ }^{\circ} \mathrm{C}$ until use. The follow-up time lasted up to February 2018, and ranged from 1 to 60 months (median, 42 months). The overall survival (OS) was defined as the length of time from the end of surgery to mortality from any cause.

\section{Informed consent}

Written informed consent was obtained from all participants included in this study.

\section{Ethical approval}

The research related to human use complied with all the relevant national regulations and institutional policies and was performed in accordance with the tenets of the Helsinki Declaration (as revised in 2013). The present study was approved by the Ethics Committee of the Affiliated Hospital of Nantong University. Experiments were performed under 
a project license [No.: SYXK(SU)2017-0046] granted by ethics committee board of Nantong University, in compliance with national or institutional guidelines for the care and use of animals.

\section{Cell culture and transfection}

Eca109, KYSE150, TE1, and TE13 EC cell lines and normal esophageal epithelial cells HEEC were purchased from The Cell Bank of Type Culture Collection of the Chinese Academy of Sciences. All cells were authenticated by short tandem repeat profiling (STR). Cells were cultured in RPMI-1640 medium (Gibco, Grand Island, NY, USA, Cat no. 31800) containing 10\% fetal bovine serum (FBS, Invitrogen, Carlsbad, CA, USA) in a $5 \%$ $\mathrm{CO}_{2}$ incubator at $37^{\circ} \mathrm{C}$. Cells were passaged every 2 days to collect cells in the logarithmic growth phase. The cells were inoculated the day before transfection and transfected when they reached $60-80 \%$ confluence. The small hairpin RNA (shRNA) targeting HAGLROS was from Invitrogen (CA, USA). The HAGLROS full-length complementary cDNA was synthesized by Invitrogen (CA, USA) and cloned into the pc-DNA3.1 expression vector (Takara Bio, Inc., Shiga, Japan). The miR-206 mimic was purchased from Shanghai GenePharma Co., Ltd. (Shanghai, China). Transfected plasmid vectors were prepared by DNA Midiprep kits (Qiagen GmbH, Hilden, Germany). According to the Qiagen instructions, EC cells were transfected using Lipofectamine ${ }^{\circledR} 2000$. The HAGLROS shRNA and control sequences were as follows: HAGLROS shRNA, 5'-CACCGCCTATTTACTGGCA GGAGTTTCTCGAGCTATTCCTTCAGCCAGTAC CC-3'; and control shRNA, 5'-GATCCCCTTCTCCGA ACGTGTCACGTTTCAAGAGAACGTGACACGTTC GGAGAATTTTTGGAAA-3'.

\section{Reverse transcription-quantitative PCR (RT-qPCR)}

Total RNA was isolated from ESCC cells by TRIzol ${ }^{\circledR}$ reagent (Invitrogen; Thermo Fisher Scientific, Inc.). Reverse transcriptase (Takara Bio, Inc.) or TaqMan ${ }^{\circledR}$ miRNA RT (Thermo Fisher Scientific, Inc.) kits were used to reverse transcribe RNA into cDNA. qPCR was performed using the SYBR-Green PCR Master Mix kit (Takara Bio, Inc., Shiga, Japan). The relative expression of genes was calculated using the $2^{-\Delta \Delta \mathrm{Cq}}$ method (21). GAPDH and U6 served as internal references. The primer sequences were as follows: HAGLROS-forward
(F), 5'-TACACCCAGAGAGGGACGAA-3'; HAGLROSreverse (R), 5'-CCCACACAAATACTCCTGCCA-3'; GAPDH-F, 5'-AGCCACATCGCTCAGACAC-3'; GAPDH-R，5'-GCCCAATACGACCAAATCC-3'; miR-206-F, 5'-CCACACACTTCCTTACATTCCA-3'; miR-206-R, 5'-CGAGCACAGAATTAATACGAC-3'; U6-F, 5'-CTCGCTTCGGCAGCACA-3'; and U6R, 5'-AACGCTTCACGAATTTGCGT-3'. PCR amplification was carried out using an initial denaturing step at $94^{\circ} \mathrm{C}$ for $3 \mathrm{~min}$, then 30 cycles of denaturation at $94{ }^{\circ} \mathrm{C}$ for $30 \mathrm{sec}$, annealing at $56^{\circ} \mathrm{C}$ for $30 \mathrm{sec}$, and extension at $72{ }^{\circ} \mathrm{C}$ for $30 \mathrm{sec}$, followed by a further extension at $72{ }^{\circ} \mathrm{C}$ for $7 \mathrm{~min}$. Thermal cycling and quantitative detection were conducted with a StepOnePlus Real-Time PCR system (Applied Biosystems; Thermo Fisher Scientific, Inc.).

\section{Cell Counting Kit-8 (CCK-8) assay}

Eca109 and KYSE150 cells $\left(1 \times 10^{3}\right.$ cells/well $)$ were plated into a 96-well plate and incubated for $0,24,48,72$, and $96 \mathrm{~h}$. Each well was supplemented with $10 \mathrm{~mL}$ of CCK-8 reagent, then the absorbance was measured at $450 \mathrm{~nm}$ using a microplate reader (Molecular Devices, Silicon Valley, CA, USA).

\section{Cell apoptosis and cell cycle detection}

Flow cytometry was used to analyze cell apoptosis and the cell cycle. For cell apoptosis detection, Eca109 and KYSE150 cells were stained with Annexin V(FITCconjugated)/propidium iodide (PI) according to the manufacturer's proposal. In brief, after treatment, the collected Eca109 and KYSE150 cells were washed 2 times using pre-cold Buffer for Cell Staining, then cells were resuspended in the staining mixture $(1 \times$ Annexin $\mathrm{V}$ binding buffer $100 \mu \mathrm{L}$, FITC Annexin V $5 \mu \mathrm{L}$ and PI solution $10 \mu \mathrm{L}$ ) and incubated for $15 \mathrm{~min}$ in the dark room temperature environment. The detection and analysis were by the flow cytometry (Becton Dickinson, San Jose, CA, USA). Cell cycle analyses were using the flow cytometer (BectonDickinson, San Jose, CA, USA) according to the standard procedure. Eca109 and KYSE150 cells were collected and fixed with $70 \%$ ethanol of $500 \mu \mathrm{L}$ overnight at temperature of $-20^{\circ} \mathrm{C}$. Then the cells were washed with pre-cold phosphate buffered saline (PBS) 2 times and stained with PI solution $500 \mu \mathrm{L}(50 \mu \mathrm{g} / \mathrm{mL})$ for $15 \mathrm{~min}$ in the dark at $37^{\circ} \mathrm{C}$ environment. The results were derived from 3 independent experiments. 


\section{Transwell assay}

The Transwell assay was performed to detect the invasive capacity of cells by Transwell chambers (BD Biosciences, New Jersey, USA) using a 24-well 8-mm pore filer (Corning, Inc.). $2 \times 10^{5}$ transfected Eca109 or KYSE150 cells were seeded into the upper chamber with serum-free medium, which was coated with $12.5 \mathrm{mg}$ Matrigel (BD Biosciences), while the lower chamber was filled with complete medium (including 20\% FBS). After $24 \mathrm{~h}$ for $37^{\circ} \mathrm{C}$ incubation, the invaded cells on the bottom surface of the membrane were fixed with $4 \%$ paraformaldehyde fixative and then stained with $0.1 \%$ crystal violet for $15 \mathrm{~min}$ at room temperature. Subsequently, the cells were visualized with an inverted microscope (Olympus, Japan).

\section{Wound healing assay}

The same number $\left(1.5 \times 10^{5}\right.$ cells/well $)$ of transfected Eca109 or KYSE150 cells were seeded into a 6-well plate and cultured at $37{ }^{\circ} \mathrm{C}$ overnight. Once the cells were completely attached, they were scraped off by plastic, creating a wound in the middle of the plate. The cells were washed and the medium was replaced by serum-free medium. Images of the wound were taken with a microscope every 12 hours for 48 hours.

\section{RNA-binding protein immunoprecipitation (RIP) assays}

RIP assays were conducted using a Magna RIP ${ }^{\mathrm{TM}}$ RNABinding Protein Immunoprecipitation kit (EMD Millipore, Temecula, CA, USA) according to the manufacturer's proposal. The RIP lysis buffer was used to treat with the transfected cells. Next, the cell extract $(100 \mathrm{~mL})$ was incubated overnight at $37^{\circ} \mathrm{C}$ with RIP buffer (EMD Millipore) containing magnetic beads that conjugated with human anti-AGO2 (1:200; cat. no. ab32381; Abcam, Cambridge, UK) or anti-IgG (1:500; cat. no. ab190495; Abcam) antibodies. After antibody recovery by protein A/G beads (EMD Millipore), RT-qPCR was performed to determine the expression levels of HAGLROS in the precipitates. $\mathrm{IgG}$ was confirmed as a negative control to normalize RNA immunoprecipitates.

\section{Western blot analysis}

KYSE150 and Eca109 cells were lysed in RIPA buffer (Beyotime, Shanghai, China), and the total protein was isolated by adding $150-250 \mu \mathrm{L}$ lysate into a 6-well plate. Next, $20 \mu \mathrm{g}$ proteins per lane were separated by $10 \%$ SDSPAGE (EMD Millipore) and then transferred to PVDF membranes. Subsequently, the PVDF membranes were blocked with TBST solution (containing 5\% fat-free milk) at room temperature for $2 \mathrm{~h}$ and then incubated at $4{ }^{\circ} \mathrm{C}$ with the corresponding primary antibodies overnight. The dilution ratios as follows: anti-proliferating cell nuclear antigen (PCNA; 1:1,000; Santa Cruz Biotechnology, Inc., CA, USA), anti-cyclin D1 (1:1,000; Santa Cruz Biotechnology, Inc.), anti-Bcl-xL (1:1,000; Santa Cruz Biotechnology, Inc.), anti-caspase 3 (1:1,000; Santa Cruz Biotechnology, Inc.), and anti-GAPDH (1:1,000; Santa Cruz Biotechnology, Inc.). Afterwards, the membranes were incubated with corresponding secondary antibodies (Abcam) for $2 \mathrm{~h}$ at $37^{\circ} \mathrm{C}$. ChemiDoc ${ }^{\mathrm{TM}}$ Imaging detection systems (Bio-Rad Laboratories, CA, USA) were applied to visualize the immunoblots.

\section{Tumor xenograft experiment}

All handled mice were performed according to the Guide for the Care and Use of Laboratory Animals (22). The animal studies were implemented according to the procedures approved by the Institutional Animal Care and Use Committee of Nantong University. The female mice of 6-week-old weighing about $20 \mathrm{~g}$ were randomly divided into two groups of four each. For inoculation into nude mice, KYSE150 cells were used. The cells were transfected with sh-HAGLROS or negative control vectors, washed with PBS, digested with trypsin (Amresco, WA, USA, Cat no. 0458), resuspended in RPMI-1640 medium (Gibco, Cat no. 31800) containing 10\% FBS (Invitrogen), and pooled. After centrifugation at $900 \mathrm{rpm}$ for 3 minutes, cells were resuspended in Matrigel (BD Biosciences)-RPMI $1640(1: 1)$ at a concentration of $5 \times 10^{6}$ cells per $100 \mu \mathrm{L}$. Six-week-old female NOD/SCID mice were purchased from the Shanghai Experimental Animal Center of the Chinese Academy of Sciences (Shanghai, China) and maintained under specific pathogen-free conditions. The cell/Matrigel mixture $(100 \mu \mathrm{L})$ was injected into the backs of the mice. The health and behavior of mice were monitored daily and tumor volume was recorded every 7 days using the following formula: volume $\left(\mathrm{mm}^{3}\right)=$ width $^{2} \times$ length $/ 2$. The 28 days later after the injection, the mice were put into the euthanasia box and $\mathrm{CO}_{2}$ was injected into the box at a rate of $10-30 \%$ per minute instead of the volume of the euthanasia box. Mice were observed for another 2 minutes 
to determine animal death and the final volume of tumor tissue was recorded.

\section{Bioinformatics prediction}

Two prediction algorithms for the interaction between lncRNAs and miRNAs were applied, lncRNASNP (http:// bioinfo.life.hust.edu.cn/lncRNASNP/\#!/predict) and RegRNA 2.0 (http://regrna2.mbc.nctu.edu.tw), in order to evaluate the targeted miRNAs of HAGLROS, and miRNAs with complementary binding sites to HAGLROS were identified. Four algorithms for predicting miRNA target genes were applied: TargetScan (http://targetscan.org), miRTarBase (http://mirtarbase.mbc.nctu.edu), miRWalk (http://mirwalk.mum.uniheidelberg.deg.php), and miRDB (http://mirdb.org/miRDB/).

\section{Dual luciferase reporter assay}

The pmirGLO-HAGLROS-wild-type (WT)/mutant (Mut) and pmirGLO-notch receptor 3 (NOTCH3)-WT/Mut reporters were obtained from Shanghai GenePharma Co., Ltd. MiR-206 mimics or miR-control were co-transfected with the aforementioned reporters into EC cells. Upon co-transfection for $48 \mathrm{~h}$, the relative luciferase activity was detected with a luminometer (PerkinElmer Life Sciences, Boston, MA, USA) using the Dual-Luciferase Reporter Assay System (Promega, Madison WI, USA) according to the manufacturer's protocol.

\section{Statistical analysis}

All experiments were repeated more than 3 times independently in this study. Differences between groups were assessed by a paired, two-tailed Student's $t$-test. Statistical analyses were conducted with SPSS 19.0 software. Data are presented as the mean \pm standard deviation (SD). The significance of differences was estimated by Student's $t$-test or one-way analysis of variance (ANOVA). When ANOVA analyzed significant differences, then the Dunnett's post hoc $t$-test method was used to analyze between each experimental group and the control group. The Kaplan-Meier method was used for survival analysis, and the log-rank test was used to analyze the difference between the high expression group and the low expression group. $\mathrm{P}<0.05$ was considered significant difference statistically.

\section{Results}

\section{HAGLROS is upregulated in ESCC tissues and predicts poor prognosis}

To assess the role of HAGLROS in ESCC, its expression profile in 182 ESCC tissue samples and 288 normal tissue samples was acquired from the Gene Expression Profiling Interactive Analysis (GEPIA) database (http://gepia. cancer-pku.cn/index.html). Highly increased expression of HAGLROS in EC tissues vs. adjacent normal tissues was observed $(\mathrm{P}<0.05$; Figure $1 A)$. Subsequently, the expression of HAGLROS in tissue samples from 76 patients with ESCC was validated. RT-qPCR data showed that the expression of HAGLROS was markedly increased in ESCC tissues compared with matched non-tumor tissues (Figure 1B). The expression of this molecule was further examined in EC cell lines (TE1, TE13, KYSE150, and Eca109) and in the normal human esophageal epithelial cell line HEEC, which was used as a control. As shown in Figure $1 C$, RT-qPCR data indicated that the expression level of HAGLROS was significantly increased in EC cell lines compared with HEEC cells. These results suggested that HAGLROS was upregulated in EC tissues and cell lines. Kaplan-Meier survival analyses indicated that high HAGLROS expression was correlated with poor prognosis in patients with ESCC. Samples were divided into expression high $(\mathrm{n}=40)$ and low $(\mathrm{n}=36)$ groups based on the HAGLROS median value. As indicated in Table 1, high expression of HAGLROS was significantly associated with tumor differentiation and tumor node metastasis (TNM) stage. However, no significant relationships were found between HAGLROS expression and the age, sex, tumor size, and invasive depth of patients with ESCC. Using Kaplan-Meier analysis, it was found that HAGLROS elevation predicted poor prognosis in patients with EC $(\mathrm{P}=0.01$; Figure 1D). Multivariate analysis further showed that the expression level of HAGLROS could be regarded as an independent prognostic factor for tumor differentiation staging in patients with EC (Table 2). These findings suggest that increased expression of HAGLROS is involved in the malignant progression of EC.

\section{Silent HAGLROS is negatively associated with malignant behavior in EC cells}

RT-qPCR was used to study the expression of HAGLROS in EC cell lines. Compared with the expression levels 
A

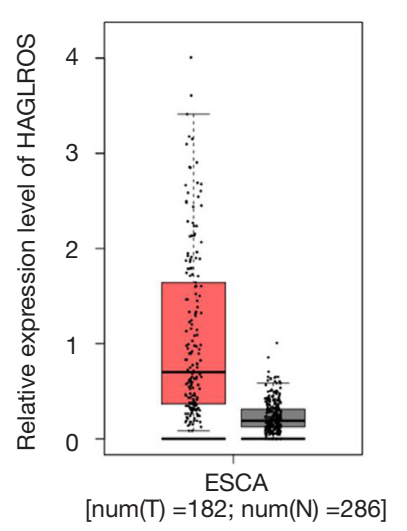

C

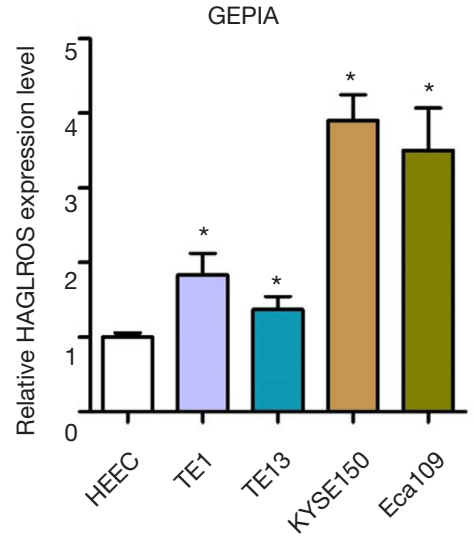

B
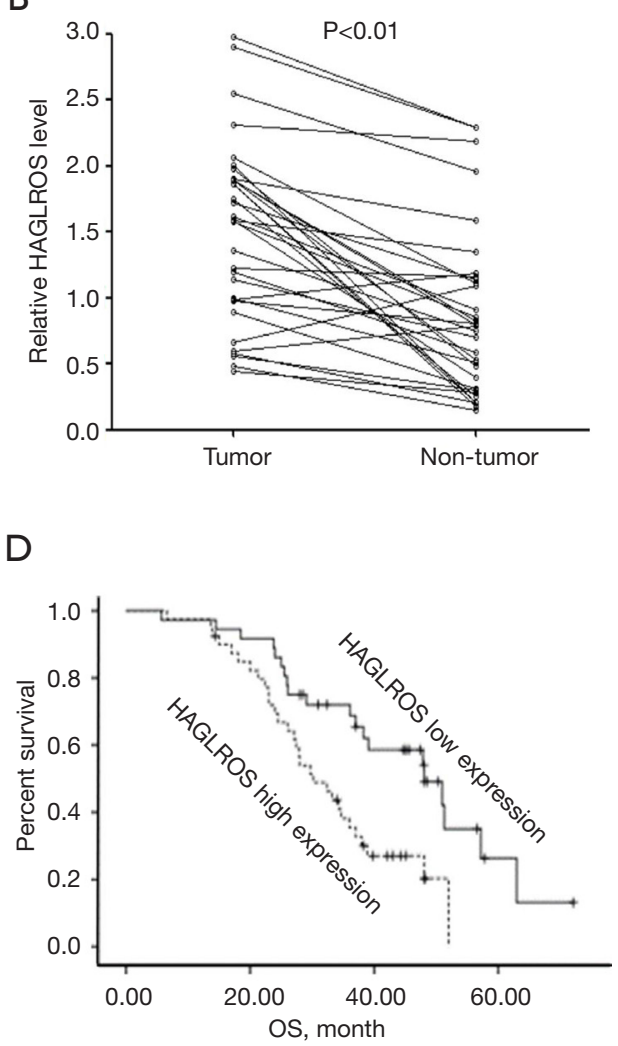

Figure 1 Expression profile of HAGLROS in EC and its association with prognosis. (A) Box plot showing the differential expression of HAGLROS in $182 \mathrm{EC}$ and 286 normal tissues in the GEPIA database. (B) RT-qPCR analysis verified that HAGLROS expression was upregulated in ESCC tissue compared with normal tissues. (C) The expression levels of HAGLROS in EC and normal human esophageal epithelial cell lines were determined by RT-qPCR. (D) Patients with high HAGLROS expression had shorter survival times than patients with low HAGLROS expression. *, $\mathrm{P}<0.05$. HAGLROS, HAGLR opposite strand lncRNA; lncRNA, long non-coding RNAs; EC, esophageal cancer; GEPIA, Gene Expression Profiling Interactive Analysis; RT-qPCR, reverse transcription-quantitative PCR; ESCC, esophageal squamous cell carcinoma; ESCA, esophageal carcinoma.

in normal esophageal epithelial cells, HAGLROS was overexpressed in TE1, TE13, KYSE150, and Eca109 cells. These results confirm the upregulation of HAGLROS expression in EC. To study the role of HAGLROS in the biological behavior of ESCC, loss of function measurements were conducted in vitro. Due to the high expression of HAGLROS in the KYSE150 and Eca109 cell lines, these cell lines were selected for loss of function studies. Plasmids containing sh-HAGLROS were constructed for transfection of KYSE150 and Eca109 cells. RT-qPCR revealed that shRNA significantly reduced the expression of HAGLROS in KYSE150 and Eca109 cells (Figure 2A,2B). The results of the CCK- 8 assay showed that transfection with sh-
HAGLROS significantly inhibited the proliferation of KYSE150 and Eca109 cells (Figure 2C,2D). Flow cytometry demonstrated that the downregulation of HAGLROS expression could induce cell cycle arrest and apoptosis (Figure 2E,2F).

\section{Low expression of HAGLROS can induce decreased invasive and migratory abilities in EC cells}

To further confirm the effect of HAGLROS on the malignant behavior of $\mathrm{EC}$ cells, the invasion and migration of KYSE150 and Eca109 cells transfected with shHAGLROS was detected by the Transwell assay. Compared 
Table 1 The association between HAGLROS expression and clinicopathological factors of ESCC patients

\begin{tabular}{|c|c|c|c|c|}
\hline \multirow[b]{2}{*}{ Clinical parameters } & \multirow{2}{*}{$\begin{array}{l}\text { Total } \\
(n=76)\end{array}$} & \multicolumn{2}{|c|}{ HAGLROS expression ${ }^{a}$} & \multirow[b]{2}{*}{$P$ value } \\
\hline & & $\begin{array}{l}\text { Low level } \\
\qquad(n=36)\end{array}$ & $\begin{array}{l}\text { High level } \\
\quad(n=40)\end{array}$ & \\
\hline Gender & & & & 0.770 \\
\hline Male & 33 & 15 & 18 & \\
\hline Female & 44 & 21 & 22 & \\
\hline Age (years) & & & & 0.749 \\
\hline$\leq 60$ & 31 & 14 & 17 & \\
\hline$>60$ & 45 & 22 & 23 & \\
\hline Tumor size (cm) & & & & 0.711 \\
\hline$\leq 3 \mathrm{~cm}$ & 30 & 15 & 15 & \\
\hline$>3 \mathrm{~cm}$ & 46 & 21 & 25 & \\
\hline Differentiation & & & & $0.020^{*}$ \\
\hline Well/moderate & 40 & 24 & 16 & \\
\hline Poor & 36 & 12 & 24 & \\
\hline $\begin{array}{l}\text { Lymph node } \\
\text { metastasis }\end{array}$ & & & & 0.160 \\
\hline Negative & 40 & 22 & 18 & \\
\hline Positive & 36 & 14 & 22 & \\
\hline Invasive depth & & & & 0.431 \\
\hline $\mathrm{T} 1 / \mathrm{T} 2$ & 31 & 13 & 18 & \\
\hline $\mathrm{T} 3 / \mathrm{T} 4$ & 45 & 23 & 22 & \\
\hline Distant metastasis & & & & 0.074 \\
\hline MO & 26 & 16 & 10 & \\
\hline M1 & 50 & 20 & 30 & \\
\hline TNM stage & & & & $0.002^{*}$ \\
\hline Stage $\mid / I I$ & 73 & 27 & 16 & \\
\hline Stage III/IV & 53 & 9 & 24 & \\
\hline
\end{tabular}

${ }^{a}$, statistical analysis was performed using the Pearson $\chi^{2}$ test; *, $\mathrm{P}<0.05$ was considered significant. HAGLROS, HAGLR opposite strand IncRNA; IncRNA, long non-coding RNAs; ESCC, esophageal squamous cell carcinoma; TNM, tumor node metastasis.

with the control group, cell invasion and migration abilities of the transfected sh-HAGLROS group decreased significantly (Figure 3A-3C). Consistently, the results of the wound healing assay also confirmed that sh-HAGLROS significantly reduced the migration and wound healing rates of KYSE150 and Eca109 cells (Figure 3D-3F). These findings suggest that downregulating the expression of $H A G L R O S$ can significantly inhibit the invasion and migration of EC cells.

\section{Downregulated HAGLROS significantly inbibits the proliferation of EC cells and accelerates apoptosis}

To further verify the effect of sh-HAGLROS on the proliferation, migration, apoptosis, and cell cycle regulation of EC cells, western blotting was used to detect the expression levels of proteins associated with cell proliferation, cell cycle regulation, and apoptosis in shHAGLROS-transfected cell lines. The results showed that the protein expression levels of PCNA, cyclin D1, and $\mathrm{Bcl}-\mathrm{xL}$ were downregulated, while those of caspase 3 were upregulated (Figure $4 A-4 C$ ). These results demonstrate that downregulation of HAGLROS can significantly restrain the EC cells proliferation and accelerate apoptosis.

\section{HAGLROS promotes EC cell tumorigenesis in vivo}

To examine the effect of sh-HAGLROS in a nude mouse xenotransplantation model, the KYSE150 cell line was used as a control. Six-week-old female mice were randomly divided into two groups of four each. The expression levels of HAGLROS in sh-HAGLROS group were significantly decreased compared to sh-NC group (Figure 5A). KYSE150 cells that had been transfected with sh-HAGLROS or negative control vectors were then inoculated into nude mice subcutaneously. It was found that sh-HAGLROS significantly inhibited tumorigenesis in vivo, and a significant decrease in tumor volume was observed compared with the control (Figure 5B,5C).

\section{HAGLROS participates in the HAGLROS/miR-206/ $\mathrm{NOTCH} 3$ regulatory axis in EC cells}

There is increasing evidence that lncRNAs act as ceRNAs to regulate the functions of miRNAs in the cytoplasm (17-20). To assess whether HAGLROS acts as a sponge of miR-206 to promote the biological behavior of EC cells, the present study further analyzed the downstream pathway of HAGLROS. Two prediction algorithms for the interaction between IncRNAs and miRNAs were applied, lncRNASNP and RegRNA 2.0, in order to evaluate the targeted miRNAs of HAGLROS, and it was found that miR-206 had complementary binding sites 
Table 2 Cox proportional hazards model analysis of prognostic factors

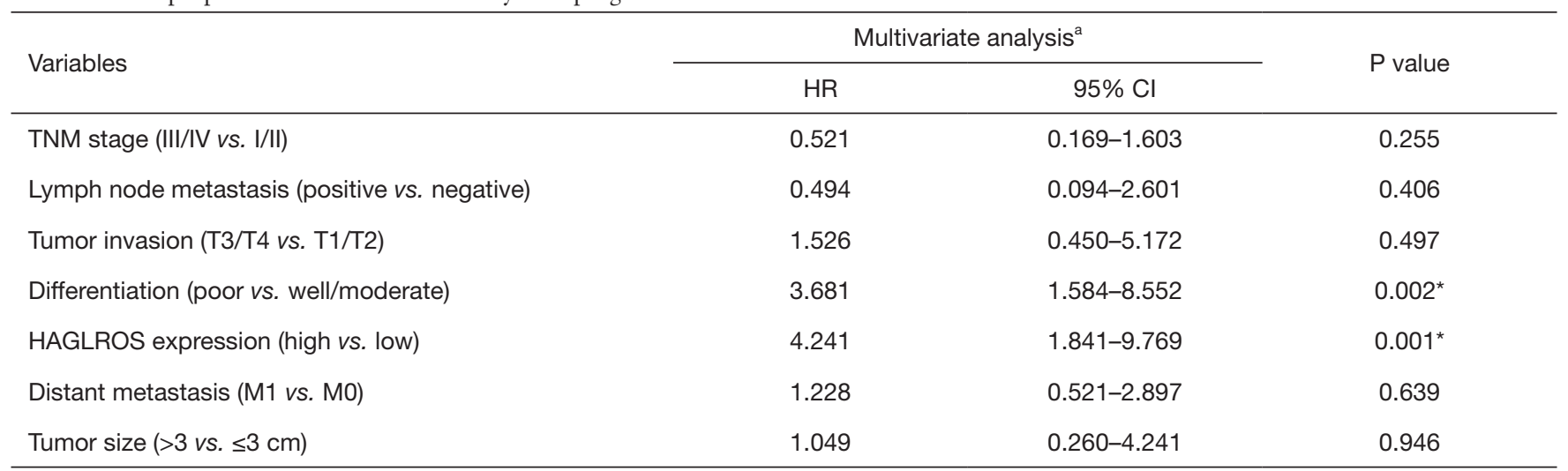

a , statistical analyses were performed using Cox regression analysis; * $\mathrm{P}<0.05$ was considered significant. $\mathrm{HR}$, hazard ratio; $\mathrm{Cl}$, confidence interval; TNM, tumor node metastasis; HAGLROS, HAGLR opposite strand IncRNA; IncRNA, long non-coding RNAs.

to HAGLROS (Figure $6 A, 6 B$ ). It was also observed that miR-206 was downregulated in EC cells (Figure 6C). The expression of miR-206 was upregulated in the 4 cell lines transfected with sh-HAGLROS (Figure 6D). These results suggest that the expression level of miR-206 in EC may be negatively correlated with the expression level of $H A G L R O S$. To verify whether HAGLROS can act as a ceRNA to make a regulation of miR-206 function in the cytoplasm, a luciferase vector for WT and Mut HAGLROS was constructed. The luciferase reporter assay showed that overexpression of miR-206 significantly reduced the luciferase activity of WT HAGLROS, while Mut reporter vectors showed no change in luciferase activity (Figure $6 E, 6 F$ ). It is well known that miRNAs bind to their target genes, resulting in post-transcriptional suppression in an AGO2-dependent manner (23). To determine the interaction between miR-206 and HAGLROS, antiAGO2-RIP was used to detect whether miR-206 regulated HAGLROS in an AGO2-dependent manner. As shown in Figure 6G, the HAGLROS levels that precipitated with AGO2 were higher than those of normal $\mathrm{IgG}$, suggesting that HAGLROS was also present in AGO2-associated RNA-induced silencing complexes. These results suggest that HAGLROS binds directly to endogenous miR-206 in EC cells. The downstream target gene of miR-206 was next evaluated in the present study. Using bioinformatics methods (TargetScan, miRTarBase, miRWalk, and miRDB), 9 potential candidate genes were predicted to be downstream targets for miR-206, and interaction sites were identified on the NOTCH3 gene (Figure 6H,6I). Luciferase vectors for WT and Mut NOTCH3 were constructed, and luciferase analysis showed that overexpression of miR-
206 significantly reduced the luciferase activity of WT $\mathrm{NOTCH} 3$, while Mut reporter vectors showed no significant change in luciferase activity (Figure 67,6K). Overall, HAGLROS, which serves as a ceRNA and is competitively targeted by miR-206, participates in the formation of the regulatory axis of HAGLROS-miR-206-NOTCH3 in EC cells.

\section{HAGLROS rescues the malignant invasiveness of EC by antagonizing the silencing of miR-206 on NOTCH3}

Although the present study has demonstrated that HAGLROS is involved in the formation of the HAGLROS/ miR-206/NOTCH3 regulatory axis in EC cells, it is not clear whether HAGLROS affects the biological function of EC cells through the miR-206/NOTCH3 axis. Therefore, vectors overexpressing $H A G L R O S$ were used to carry out cell physiological function rescue experiments. Prior to this, western blot analysis of KYSE150 and Eca109 cells showed that HAGLROS overexpression could antagonize miR-206 silencing of $\mathrm{NOTCH} 3$ to restore NOTCH3 expression (Figure $7 A, 7 B$ ). In the rescue experiments, HAGLROS overexpression enabled KYSE150 and Eca109 cells to overcome the decline in invasion caused by overexpression of miR-206 (Figure $8 A-8 C$ ). The results of the wound healing assay also confirmed that transfection plasmids expressing HAGLROS significantly increased the migration of KYSE150 and Eca109 cells (Figure 8D-8F). These results strongly suggest that $H A G L R O S$ can act as a miR206 sponge to modulate the biological function of EC cells, thereby eliminating the inhibitory effect of miR-206 on NOTCH3. 

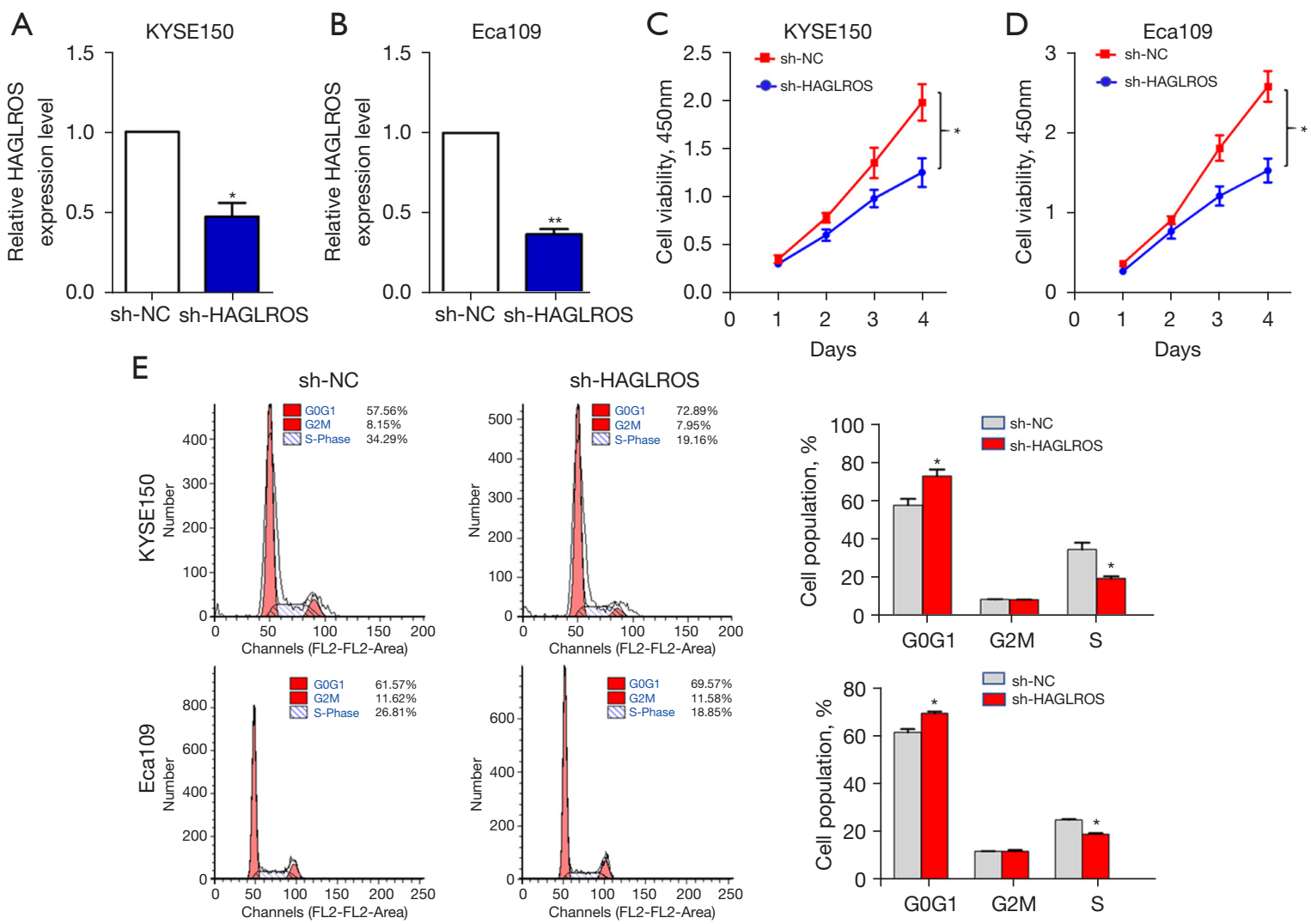

$\mathrm{F}$
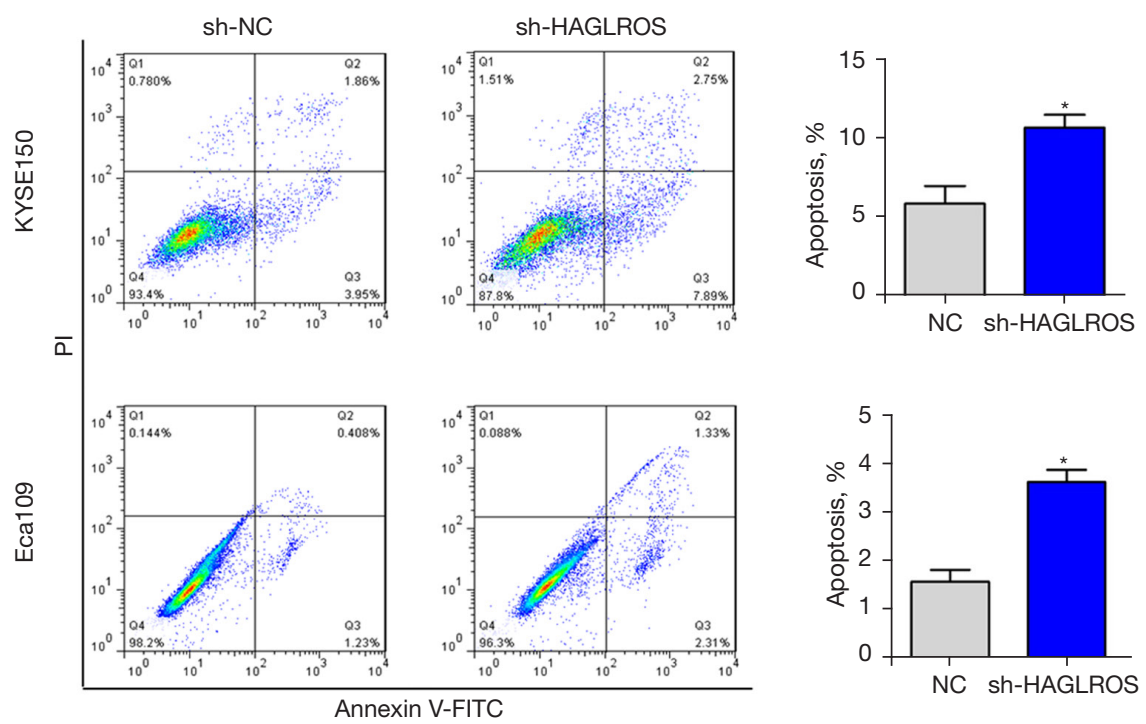

Figure 2 Association between HAGLROS and cell proliferation, apoptosis, and cell cycle regulation in EC cell lines. (A,B) RT-qPCR showed the silencing efficiency of HAGLROS in KYSE150 and Eca109 cells. (C,D) The CCK-8 assay showed that silencing HAGLROS reduced the proliferation of KYSE150 and Eca109 cells. (E) Flow cytometry analysis showed that silencing HAGLROS induced cell cycle arrest in KYSE150 and Eca109 cells. (F) Flow cytometry analysis showed that downregulation of HAGLROS induced cell apoptosis. *, $\mathrm{P}<0.05$; **, $\mathrm{P}<0.01$. HAGLROS, HAGLR opposite strand lncRNA; lncRNA, long non-coding RNAs; EC, esophageal cancer; RT-qPCR, reverse transcription-quantitative PCR; CCK-8, Cell Counting Kit-8. 
A

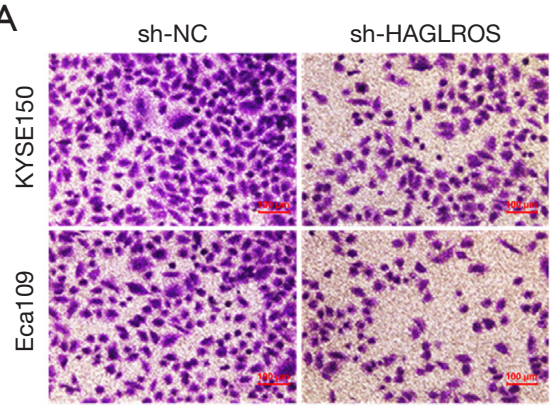

B

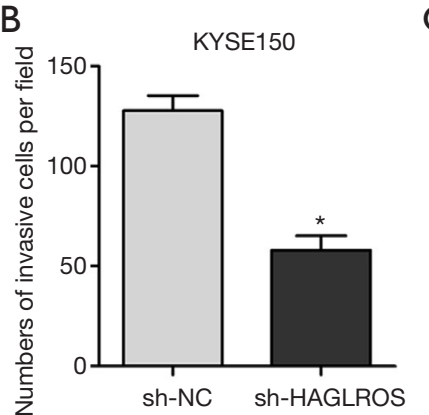

C

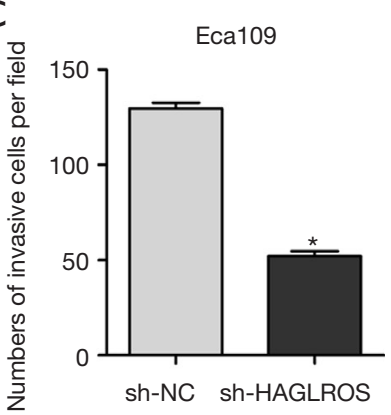

D

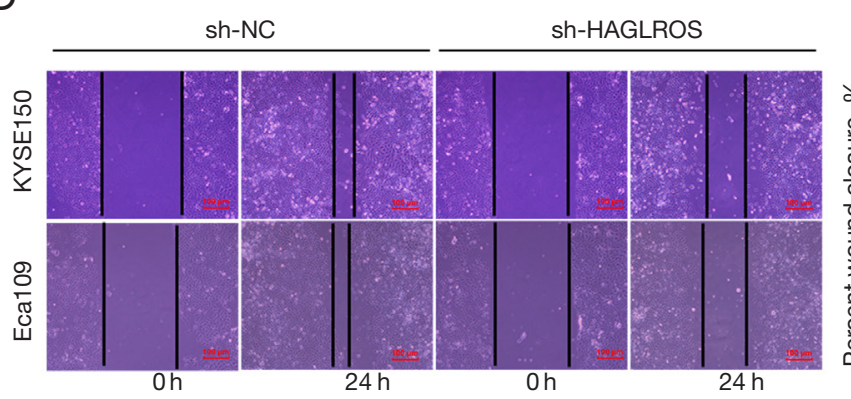

E

KYSE150

F

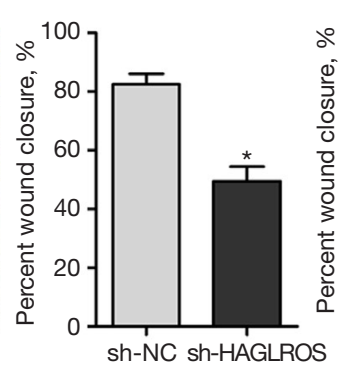

Eca109

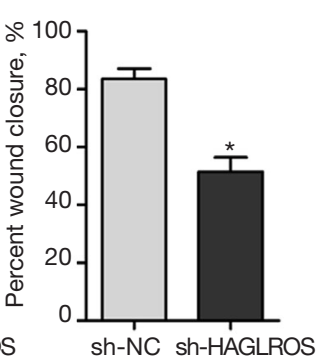

Figure 3 HAGLROS is associated with the malignant behavior of EC. (A-C) The Transwell assay and crystal violet staining showed that silencing HAGLROS inhibited the invasion of KYSE150 and Eca109 cells. (D-F) Cell migration was monitored by the wound healing assay with filter shooting. All the experiments were carried out in triplicate. *, $\mathrm{P}<0.05$. HAGLROS, HAGLR opposite strand lncRNA; lncRNA, long non-coding RNAs; EC, esophageal cancer.

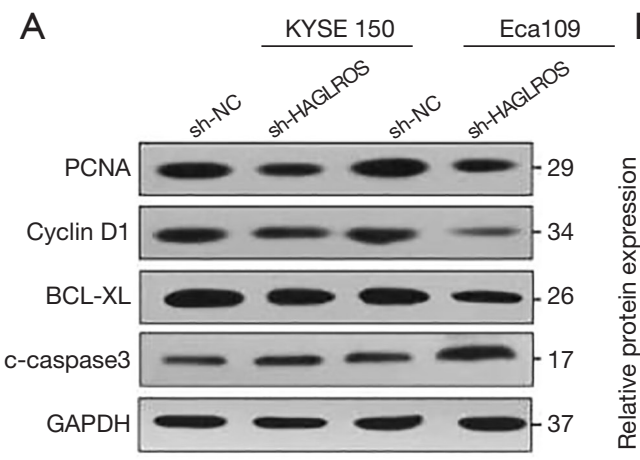

B

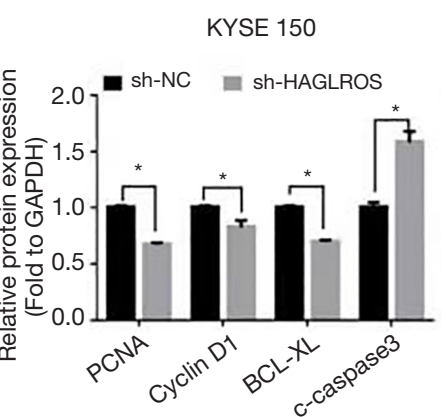

C

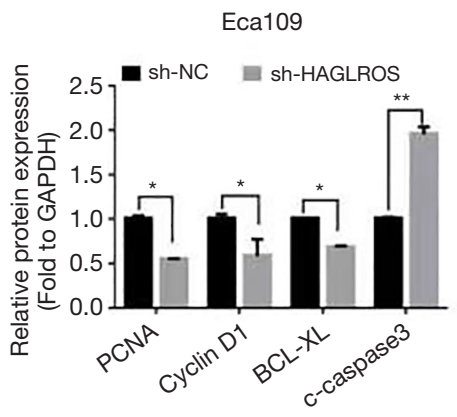

Figure 4 Effects of HAGLROS knockdown on the proliferation and apoptosis of EC cells. (A) The levels of proteins associated with proliferation and apoptosis in KYSE150 and Eca109 cells were detected by western blotting. (B,C) The mRNA levels of molecules associated with proliferation and apoptosis in KYSE150 and Eca109 cells were determined by RT-qPCR. * $\mathrm{P}<0.05 ;{ }^{* *}, \mathrm{P}<0.01$. HAGLROS, HAGLR opposite strand lncRNA; lncRNA, long non-coding RNAs; EC, esophageal cancer; RT-qPCR, reverse transcription-quantitative PCR.

\section{Discussion}

Abnormal and uncontrolled cell proliferation is a hallmark of cancer, and is caused by the misregulation of the expression of various crucial molecules. Although numerous oncogenes, tumor suppressor genes, and tumor-related signaling pathways have been identified and confirmed in recent years, the pathogenesis of $\mathrm{EC}$ remains unclear (24-26). In total, $18 \%$ of ncRNAs are associated with 
A

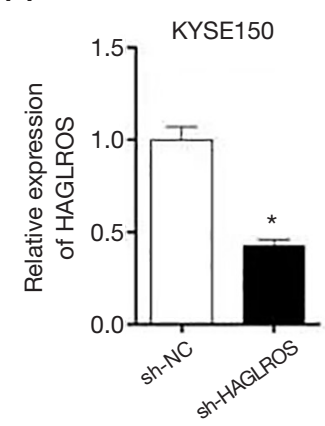

B

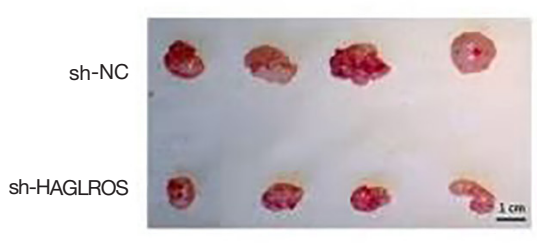

C

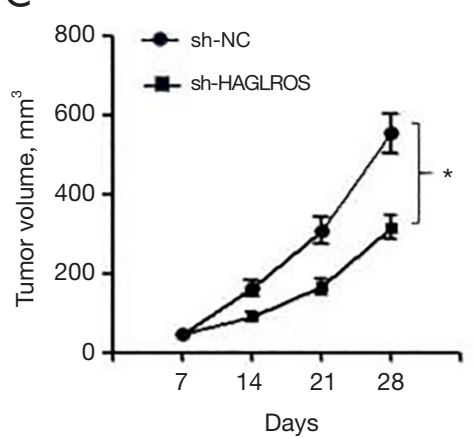

Figure 5 HAGLROS promotes EC cell tumorigenesis in vivo. (A) RT-qPCR showed the silencing efficiency of HAGLROS in KYSE150 cells. (B) KYSE150 cells transfected with negative control shRNA (sh-NC) or HAGLROS shRNA (sh- HAGLROS) were injected into nude mice $(n=4)$ respectively, which were euthanized by carbon dioxide euthanasia after 28 days. (C) Tumor volumes were analyzed every 7 days after 1 week post-injection. After 28 days, the maximum tumor volume was $603 \mathrm{~mm}^{3}$. *, $\mathrm{P}<0.05$. shRNA, small hairpin RNA; HAGLROS, HAGLR opposite strand lncRNA; lncRNA, long non-coding RNAs; EC, esophageal cancer; RT-qPCR, reverse transcription-quantitative PCR.

human tumors, while lncRNAs account for 9\%, suggesting that lncRNAs may be a major factor in carcinogenesis and cancer progression (27). LncRNAs have been found to be abnormally expressed in a variety of human tumors, including EC, and are commonly considered as tumor suppressors or oncogenes, thus regulating tumorigenesis, progression, and resistance to drug therapy (28). For example, IncRNA LOXLI-AS1 regulates the prostate cancer cell cycle, and induces cell proliferation by modulating cyclin D1 and miR-541-3p (29). LncRNA TLSNC8 inhibits tumor metastasis and promotes cell apoptosis in NSCLC by modulating the signaling pathways of interleukin 6 (IL-6)/ signal transducer and activator of transcription 3 (STAT3)/ hypoxia inducing factor (HIF) (30). Yan et al. (31) found that heart and neural crest derivatives expressed 2-AS1 (HAND2-AS1) enhances inactivation of the JAK/STAT pathway by activating miR-3118, and promotes suppressor of cytokine signaling 5 (SOCS5) expression to attenuate proliferation and migration of hepatocellular carcinoma. The above evidence suggests that targeting lncRNAs may be important for cancer therapy.

HAGLROS is a recently identified lncRNA, though currently information on HAGLROS is limited. In the present study, GEPIA was used to analyze data and found that HAGLROS was overexpressed in EC tissues. These results suggest that $H A G L R O S$ may play an important role in the progression of $\mathrm{EC}$, but the mechanism of HAGLROS in EC has not been reported thus far. Based on the data of HAGLROS expression in EC cell lines,
Eca109 and KYSE150 cells were selected to evaluate their functions, since they exhibited high expression levels of HAGLROS. Vector-transfected cell lines containing shHAGLROS were constructed, and the IncRNA level was downregulated successfully. A series of cell experiments confirmed the cancer-promoting effect of HAGLROS in EC, particularly in cell proliferation, migration, and apoptosis. These results suggest that HAGLROS may have certain value in the diagnosis and treatment of EC. However, the specific mechanism remains unclear. In addition, in terms of current research results, we believe HAGLROS could be used as a potential biomarker for risk stratification and local regional metastasis in patients with EC. But we think this requires a larger sample size study to further confirm.

Numerous studies have reported that lncRNAs are able to bind to miRNAs in the form of ceRNAs and play an important regulatory role (17-20). In the present study, miR-206 was screened by bioinformatics analysis as a candidate target. Numerous studies have shown that miR206 plays an inhibitory role in various cancer types $(32,33)$. Jiao et al. (32) found that miR-206 inhibits the proliferation and metastasis of lung cancer cells by inhibiting the AKT and ERK pathways downstream of c-Met and by blocking hepatocyte growth factor-induced epithelial-mesenchymal transition. Wang et al. (33) found that miR-206 inhibits prostate cancer cell proliferation and migration by targeting $\mathrm{C}-\mathrm{X}-\mathrm{C}$ motif chemokine ligand 11 . The present study used a dual luciferase reporter gene system to identify miR-206 
A

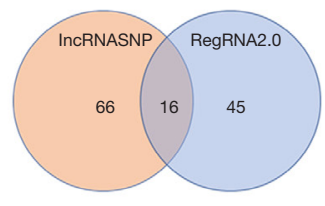

C

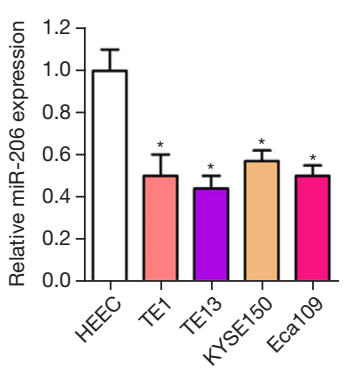

E

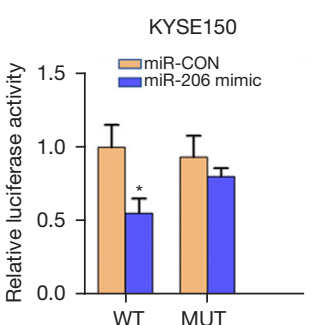

B

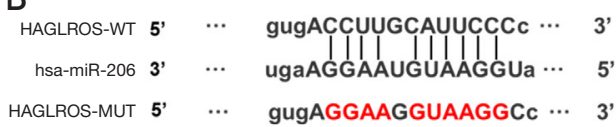

D

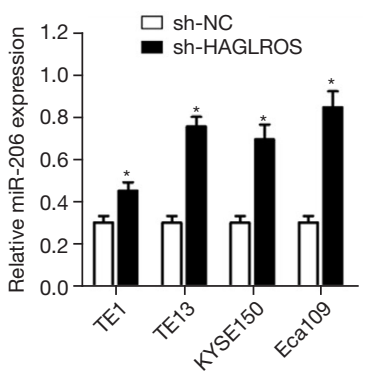

G
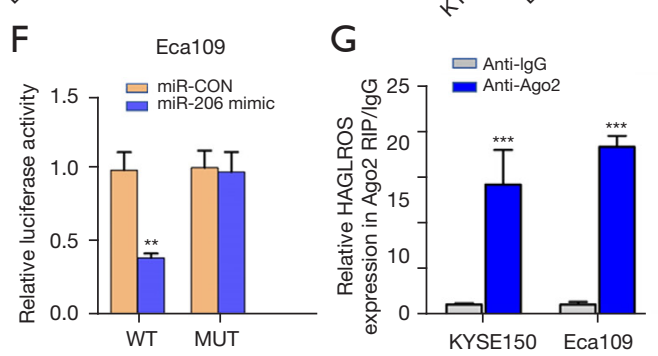

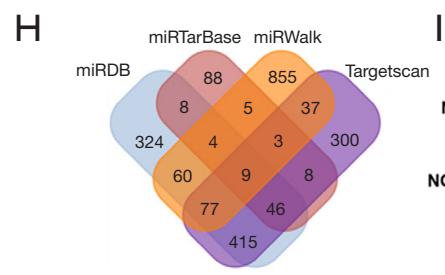
? 
A
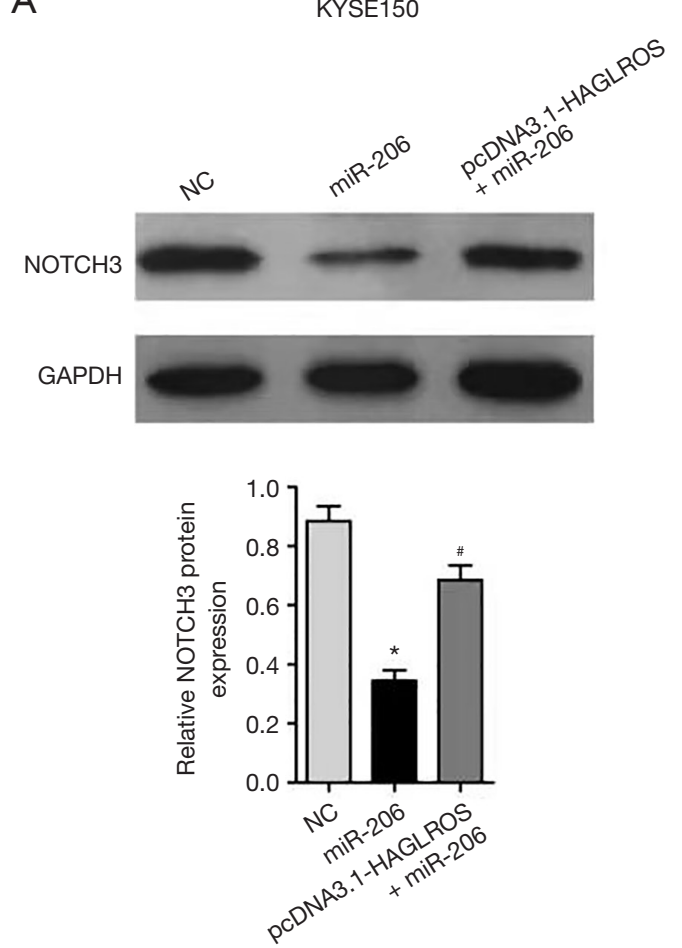

B
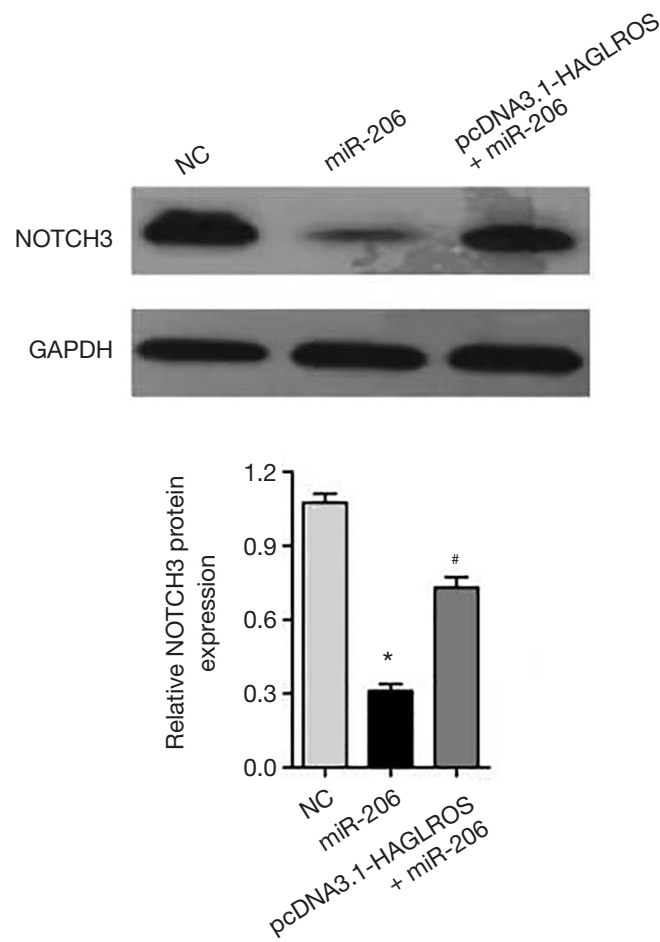

Figure $7 \mathrm{NOTCH} 3$ protein expression levels in different groups. Western blot analyses of NOTCH3 protein expression levels following treatment of (A) KYSE150 and (B) Eca109 cells with miR-negative control, miR-206, or pcDNA3.1-HAGLROS + miR-206. GAPDH was used as the control. The results were reproducible in 3 independent experiments. ${ }^{*}, \mathrm{P}<0.05$ versus the NC group; ${ }^{*}, \mathrm{P}<0.05$ versus the miR206 group. NOTCH3, notch receptor 3; miR, microRNA.

as a downstream miRNA of HAGLROS and to demonstrate that miR-206 expression was inhibited by HAGLROS. Numerous studies have demonstrated that miRNAs can cause target gene degradation or translation inhibition by pairing with 3'-UTR bases of the target gene (11-13). In the present study, $\mathrm{NOTCH} 3$ was screened as a candidate gene for miR-206 by bioinformatics analysis. A dual luciferase reporter gene system was used to identify $\mathrm{NOTCH}_{3}$ as a downstream target gene of miR-206 and to demonstrate that miR-206 inhibited NOTCH3 expression. Therefore, it was speculated that the HAGLROS/miR-206/NOTCH3 regulatory axis may be associated with the carcinogenesis of HAGLROS in EC.

Finally, we know that the radioresistance remains a major obstacle for effective treatment of EC. we did not sure about the effect of HAGLROS on radioresistance of EC. In the following study, we will study their relationship in vitro. In addition, IncRNA or mRNA are to be differentially expressed in EC through gene sequencing. If some suitable
lncRNA or mRNA are screened in EC, we believe that some other molecules as HAGLROS will suggest its prognostic value. We hope to have a more in-depth study on HAGLROS. In the follow-up research, we will further explore the molecular mechanism of EC and analysis of a wide range of pathological factors.

In conclusion, overexpression of HAGLROS in EC tissues and cells may promote cancer. Downregulation of HAGLROS may inhibit cell proliferation and induce cell apoptosis. The mechanism may be associated with downstream miR-206 and NOTCH3 signaling. The HAGLROS/miR206/NOTCH3 regulatory axis may have certain potential in the treatment and prognosis of EC.

\section{Acknowledgments}

Funding: The present study was supported by the Science and Technology Program of Nantong, China (grant Nos. JCZ20206, JCZ19077, JC2020027 and MSZ19216). 
A

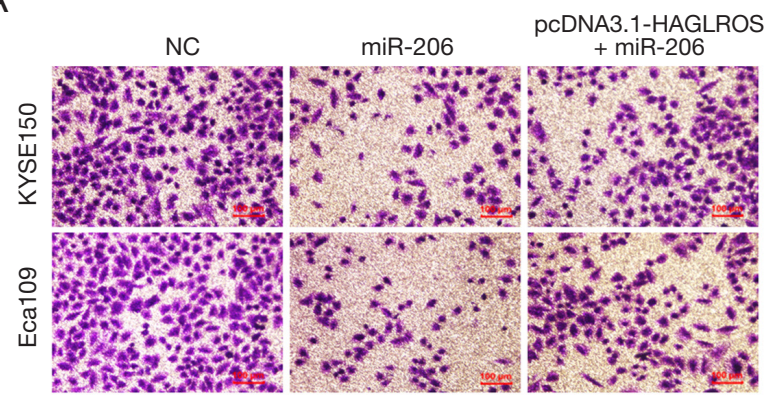

D

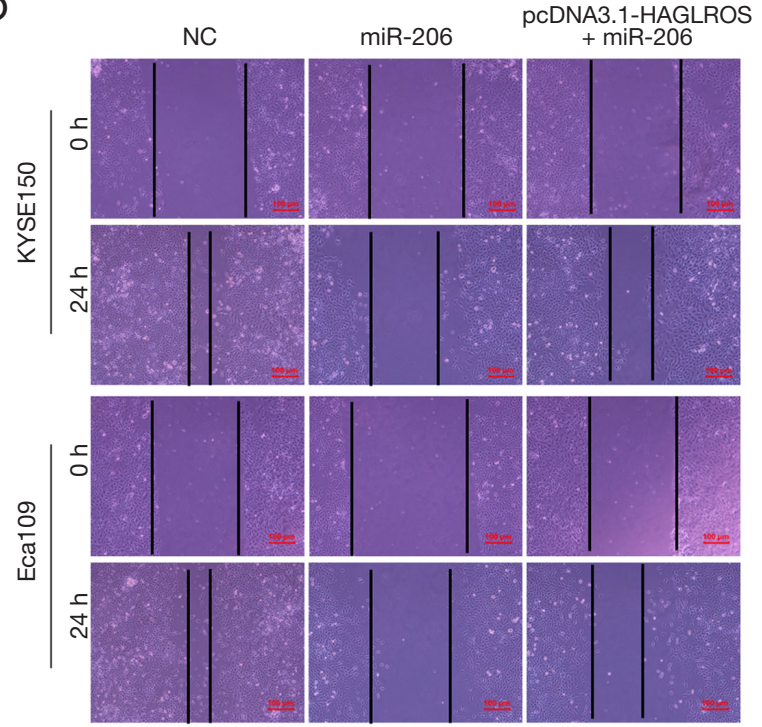

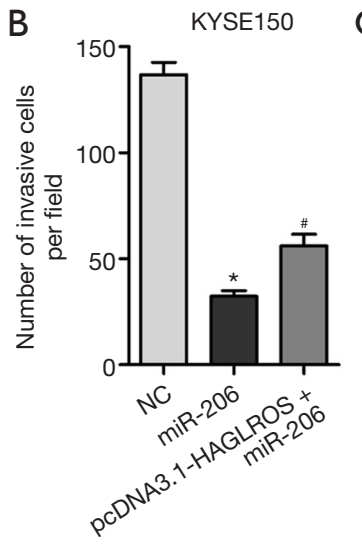

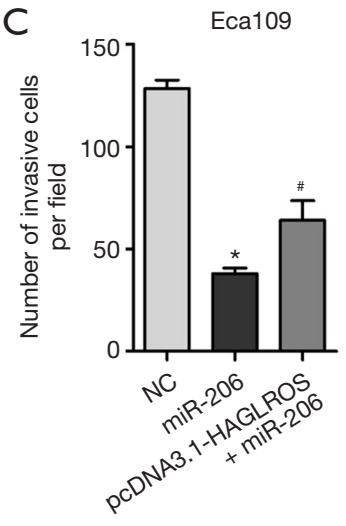

$E$

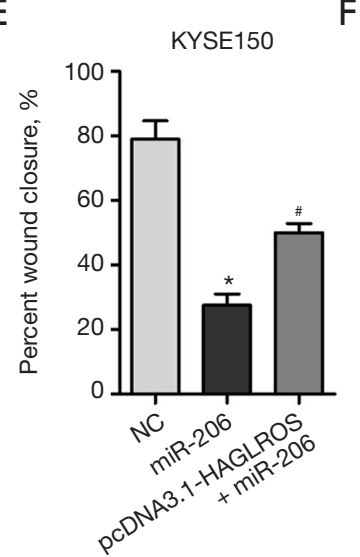

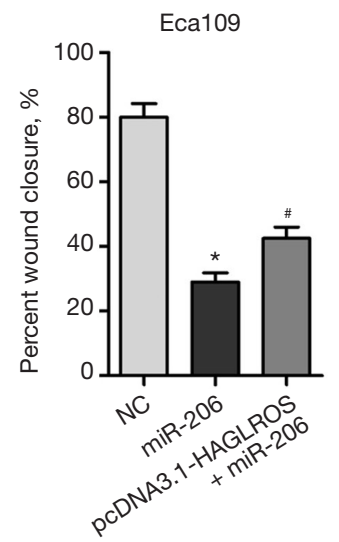

Figure 8 HAGLROS reverses the inhibitory effect of miR-206 on EC cells in vitro. (A-C) KYSE150 and Eca109 cells were treated with miRnegative control, miR-206, or pcDNA3.1-HAGLROS + miR-206. The number of invaded cells was stained with crystal violet and measured. (D-F) Cell migration was monitored by the wound healing assay with filter shooting. All the experiments were performed in triplicate. *, $\mathrm{P}<0.05$ versus the NC group; ${ }^{\#}, \mathrm{P}<0.05$ versus the miR-206 group. HAGLROS, HAGLR opposite strand lncRNA; lncRNA, long non-coding RNAs; miR, microRNA; EC, esophageal cancer.

\section{Footnote}

Reporting Checklist: The authors have completed the ARRIVE reporting checklist. Available at https://dx.doi. org/10.21037/jgo-21-586

Data Sharing Statement: Available at https://dx.doi. org/10.21037/jgo-21-586

Conflicts of Interest: All authors have completed the ICMJE uniform disclosure form (available at https://dx.doi. org/10.21037/jgo-21-586). The authors have no conflicts of interest to declare.
Ethical Statement: The authors are accountable for all aspects of the work in ensuring that questions related to the accuracy or integrity of any part of the work are appropriately investigated and resolved. The research related to human use complied with all the relevant national regulations and institutional policies and was performed in accordance with the tenets of the Helsinki Declaration (as revised in 2013). The present study was approved by the Ethics Committee of the Affiliated Hospital of Nantong University. Written informed consent was obtained from all participants included in this study. Experiments were performed under a project license [No.: 
SYXK(SU)2017-0046] granted by ethics committee board of Nantong University, in compliance with national or institutional guidelines for the care and use of animals.

Open Access Statement: This is an Open Access article distributed in accordance with the Creative Commons Attribution-NonCommercial-NoDerivs 4.0 International License (CC BY-NC-ND 4.0), which permits the noncommercial replication and distribution of the article with the strict proviso that no changes or edits are made and the original work is properly cited (including links to both the formal publication through the relevant DOI and the license). See: https://creativecommons.org/licenses/by-nc-nd/4.0/.

\section{References}

1. Shiba D, Terayama M, Yamada K, et al. Clinicopathological significance of cystatin A expression in progression of esophageal squamous cell carcinoma. Medicine (Baltimore) 2018;97:e357.

2. van Rossum PSN, Mohammad NH, Vleggaar FP, et al. Treatment for unresectable or metastatic oesophageal cancer: current evidence and trends. Nat Rev Gastroenterol Hepatol 2018;15:235-49.

3. Lagergren J, Smyth E, Cunningham D, et al. Oesophageal cancer. Lancet 2017;390:2383-96.

4. Pennathur A, Gibson MK, Jobe BA, et al. Oesophageal carcinoma. Lancet 2013;381:400-12.

5. Siegel RL, Miller KD, Jemal A. Cancer statistics, 2018. CA Cancer J Clin 2018;68:7-30.

6. Zhang L, Peng D, Sood AK, et al. Shedding light on the dark cancer genomes: long noncoding RNAs as novel biomarkers and potential therapeutic targets for cancer. Mol Cancer Ther 2018;17:1816-23.

7. Yao RW, Wang Y, Chen LL. Cellular functions of long noncoding RNAs. Nat Cell Biol 2019;21:542-51.

8. Wang CJ, Zhu CC, Xu J, et al. The IncRNA UCA1 promotes proliferation, migration, immune escape and inhibits apoptosis in gastric cancer by sponging anti-tumor miRNAs. Mol Cancer 2019;18:115.

9. Luo ML, Li J, Shen L, et al. The role of APAL/ST8SIA6AS1 lncRNA in PLK1 activation and mitotic catastrophe of tumor cells. J Natl Cancer Inst 2020;112:356-68.

10. Zheng S, Yang L, Zou Y, et al. Long non-coding RNA HUMT hypomethylation promotes lymphangiogenesis and metastasis via activating FOXK1 transcription in triple-negative breast cancer. J Hematol Oncol 2020;13:17.

11. Pishkari S, Paryan M, Hashemi M, et al. The role of
microRNAs in different types of thyroid carcinoma: a comprehensive analysis to find new miRNA supplementary therapies. J Endocrinol Invest 2018;41:269-83.

12. Farazi TA, Spitzer JI, Morozov P, et al. miRNAs in human cancer. J Pathol 2011;223:102-15.

13. Hwang HW, Mendell JT. MicroRNAs in cell proliferation, cell death, and tumorigenesis. Br J Cancer 2006;94:776-80.

14. Zheng ZQ, Li ZX, Zhou GQ, et al. Long noncoding RNA FAM225A promotes nasopharyngeal carcinoma tumorigenesis and metastasis by acting as ceRNA to sponge miR-590-3p/miR-1275 and upregulate ITGB3. Cancer Res 2019;79:4612-26.

15. Li Y, Wang H, Huang H. Long non-coding RNA MIR205HG function as a ceRNA to accelerate tumor growth and progression via sponging miR-122-5p in cervical cancer. Biochem Biophys Res Commun 2019;514:78-85.

16. Huang Y, Ni R, Wang J, et al. Knockdown of lncRNA DLX6-AS1 inhibits cell proliferation, migration and invasion while promotes apoptosis by downregulating PRR11 expression and upregulating miR-144 in non-small cell lung cancer. Biomed Pharmacother 2019;109:1851-9.

17. Chen JF, Wu P, Xia R, et al. STAT3-induced lncRNA HAGLROS overexpression contributes to the malignant progression of gastric cancer cells via mTOR signalmediated inhibition of autophagy. Mol Cancer 2018;17:6.

18. Wei $\mathrm{H}, \mathrm{Hu} \mathrm{J}, \mathrm{Pu}$ J, et al. Long noncoding RNA HAGLROS promotes cell proliferation, inhibits apoptosis and enhances autophagy via regulating miR5095/ATG12 axis in hepatocellular carcinoma cells. Int Immunopharmacol 2019;73:72-80.

19. Zheng Y, Tan K, Huang H. Long noncoding RNA HAGLROS regulates apoptosis and autophagy in colorectal cancer cells via sponging miR-100 to target ATG5 expression. J Cell Biochem 2019;120:3922-33.

20. Zhang W, Zhang Y, Xi S. Upregulation of lncRNA HAGLROS enhances the development of nasopharyngeal carcinoma via modulating miR-100/ATG14 axis-mediated PI3K/AKT/mTOR signals. Artif Cells Nanomed Biotechnol 2019;47:3043-52.

21. Livak KJ, Schmittgen TD. Analysis of relative gene expression data using real-time quantitative PCR and the 2(-Delta Delta C(T)) Method. Methods 2001;25:402-8.

22. National Research Council (US) Committee for the Update of the Guide for the Care and Use of Laboratory Animals. Guide for the Care and Use of Laboratory Animals. 8th ed. Washington (DC): National Academies Press (US), 2011. 
23. Hammond SM. An overview of microRNAs. Adv Drug Deliv Rev 2015;87:3-14.

24. Wei WT, Wang L, Liang JX, et al. LncRNA EIF3JAS1 enhanced esophageal cancer invasion via regulating AKT1 expression through sponging miR-373-3p. Sci Rep 2020;10:13969.

25. Wang X, Kutschat AP, Yamada M, et al. Bromodomain protein BRDT directs $\triangle \mathrm{Np} 63$ function and superenhancer activity in a subset of esophageal squamous cell carcinomas. Cell Death Differ 2021;28:2207-20.

26. Cheng X, Wei L, Huang X, et al. Solute carrier family 39 member 6 gene promotes aggressiveness of esophageal carcinoma cells by increasing intracellular levels of zinc, activating phosphatidylinositol 3-kinase signaling, and upregulating genes that regulate metastasis. Gastroenterology 2017;152:1985-97.e12.

27. Gao P, Wei GH. Genomic insight into the role of lncRNA in cancer susceptibility. Int J Mol Sci 2017;18:1239.

28. Hou X, Wen J, Ren Z, et al. Non-coding RNAs: new biomarkers and therapeutic targets for esophageal cancer. Oncotarget 2017;8:43571-8.

29. Long B, Li N, Xu XX, et al. Long noncoding RNA LOXL1-AS1 regulates prostate cancer cell proliferation and cell cycle progression through miR-

Cite this article as: Gai L, Huang Y, Zhao L, Li F, Zhuang Z. Long non-coding RNA HAGLROS regulates the proliferation, migration, and apoptosis of esophageal cancer cells via the HAGLROS-miR-206-NOTCH3 axis. J Gastrointest Oncol 2021;12(5):2093-2108. doi: 10.21037/jgo-21-586 541-3p and CCND1. Biochem Biophys Res Commun 2018;505:561-8.

30. Fan H, Li J, Wang J, et al. Long non-coding RNAs (lncRNAs) tumor-suppressive role of lncRNA on chromosome 8p12 (TSLNC8) inhibits tumor metastasis and promotes apoptosis by regulating interleukin 6 (IL-6)/ signal transducer and activator of transcription 3 (STAT3)/ hypoxia-inducible factor 1 -alpha $(\mathrm{HIF}-1 \alpha)$ signaling pathway in non-small cell lung cancer. Med Sci Monit 2019;25:7624-33.

31. Yan D, Jin F, Lin Y. lncRNA HAND2-AS1 inhibits liver cancer cell proliferation and migration by upregulating SOCS5 to inactivate the JAK-STAT pathway. Cancer Biother Radiopharm 2020;35:143-52.

32. Jiao D, Chen J, Li Y, et al. miR-1-3p and miR-206 sensitizes HGF-induced gefitinib-resistant human lung cancer cells through inhibition of c-Met signalling and EMT. J Cell Mol Med 2018;22:3526-36.

33. Wang Y, Xu H, Si L, et al. MiR-206 inhibits proliferation and migration of prostate cancer cells by targeting

CXCL11. Prostate 2018;78:479-90.

(English Language Editor: C. Betlzar) 